\title{
DESIGN E EDUCAÇÃO PARA ACESSIBILIDADE: MAPA MULTISENSORIAL PARA DEFICIENTES VISUAIS
}

Fernando da Silva Ramos

FACAMP - Faculdades de Campinas

fernandala@gmail.com

Ana Beatriz de Araújo Linardi

FACAMP - Faculdades de Campinas

anabeatriz.linardi@gmail.com

Flávio Valverde Garotti

FACAMP - Faculdades de Campinas

flaviovalverde@gmail.com

Vitor Damiani

FACAMP - Faculdades de Campinas

vdamiani@gmail.com

Resumo: No ano de 2015, O NIEDA ${ }^{1}$ - Núcleo Interdisciplinar de Estudos em Design e Acessibilidade da FACAMP ${ }^{2}$, desenvolveu um projeto sob demanda do Museu Exploratório de Ciências da UNICAMP: Um mapa multissensorial (tátil e sonoro), com o propósito de explicar a pessoas cegas e com baixa visão, o processo de geração e distribuição de energia em uma usina hidrelétrica. Sendo resultado da cooperação entre grupos atuantes em instituições de ensino importantes, teve como um de seus objetivos, o avanço da pesquisa aplicada e efetiva, nas áreas da educação para a acessibilidade e design universal. Neste artigo, faz-se um relato desta experiência, procurando descrever o processo de projeto e desenvolvimento do produto de design orientado à inclusão de públicos especiais, partindo-se de premissas destacadas das áreas da Educação e Tecnologia Assistiva.

Palavras-chave: Educação, Design Universal, Acessibilidade, fabricação digital

\footnotetext{
${ }^{1}$ www.nieda.com.br

${ }^{2}$ www.facamp.com.br
} 


\section{INTRODUÇÃO: CONCEITOS E BASE TEÓRICA}

O objeto de estudo deste artigo move-se pelos domínios da Educação, no campo teórico das Pedagogias Criativas, na direção de descrever como algumas premissas metodológicas, podem alavancar hipóteses de projeto de design de produto. Ou dito de outra forma, como pode o design tornar-se, por si, e de posse de seu instrumental específico, em um caminho para explicar o mundo, a partir de um referencial trazido da Educação.

A evolução dos sistemas de educação formal e não-formal, tem sido muito lenta na direção de propor soluções de acesso ao conhecimento, pelas pessoas com deficiências. Em uma cultura onde os meios visuais predominam e se banalizam, cresce a percepção do papel do designer como agente de novas maneiras de perceber o mundo, interpretar fenômenos e construir sentidos.

A luta do Design para livrar-se do estereótipo popular, que the resume a, essencialmente, sua função estética - ligada a um sentido daquilo que é frívolo e (frequentemente) desnecessário, pode encontrar um reforço substancial na associação com a Educação e a Tecnologia Assistiva, na formulação de assertivas que justifiquem a autonomia da profissão, como absolutamente fundamental para os desenvolvimentos da economia, políticas sociais e desenvolvimento das potencialidades humanas.

A perspectiva do designer, orientada a apresentar soluções concretas a problematizações abstratas de toda ordem, o deixa em condição privilegiada para reunir e processar diretrizes oriundas de áreas tão distintas, quanto sejam a engenharia de produção, neurociência, psicologia cognitiva, ergonomia, sonoplastia, tecnologia da informação, e linguagem visual, em torno do objetivo da inovação de práticas pedagógicas atualizadas. A marca da multi-interdisciplinaridade, que é a antítese da procura pela especialização, neste caso, longe de ser tratada como fragilidade formativa, é assumida como maior potencial do designer.

A utilização de modelos físicos e áudio descrições não constituem novidade à educação dirigida a públicos especiais; parece ser uma premissa consistente essa, a de associar estímulos sensoriais diversos na direção de construir narrativas mais complexas e compreensíveis. No entanto, no campo das soluções concretas (aquilo que aqui estamos chamando de hipóteses de projeto), há grande potencial para a transformação de alguns dos velhos paradigmas, na direção de criar novas metáforas e associações.

Este artigo ocupa-se prioritariamente de descrever quais são estes velhos paradigmas, quais premissas fundamentam a proposição de novas metáforas descritivas, e como esta reflexão conduziu o projeto à solução encontrada, através da descrição de um projeto de acessibilidade que teve por objetivo, tomar como referência uma maquete visual produzida com a finalidade de ilustrar o roteiro de geração, distribuição e consumo da energia elétrica, percorrendo o caminho que leva desde a barragem da usina hidrelétrica, até os meios onde esta energia é utilizada, e tornar este complexo sistema compreensível às pessoas que não possuem o sentido da visão.

\section{DESENVOLVIMENTO: RECONSTITUIÇÃO DE UM CAMINHO DE METÁFORAS E SENTIDOS}

O Museu Exploratório de Ciências da Unicamp ${ }^{3}$ foi criado com o propósito de

\footnotetext{
${ }^{3}$ http://www.mc.unicamp.br/
} 
divulgação da ciência, através da mobilização de sua comunidade acadêmica. Seu acervo é integrado em parte, por uma exposição realizada em torno tema 'Energia'.

Dentre as estações que compõem a mostra, interativas, de forma a possibilitar ao usuário vivenciar os fenômenos relacionados ao tema, há uma maquete de 4,0 m que mostra o processo de geração de energia a partir de uma usina hidrelétrica, distribuição e diferentes usos no contexto urbano.

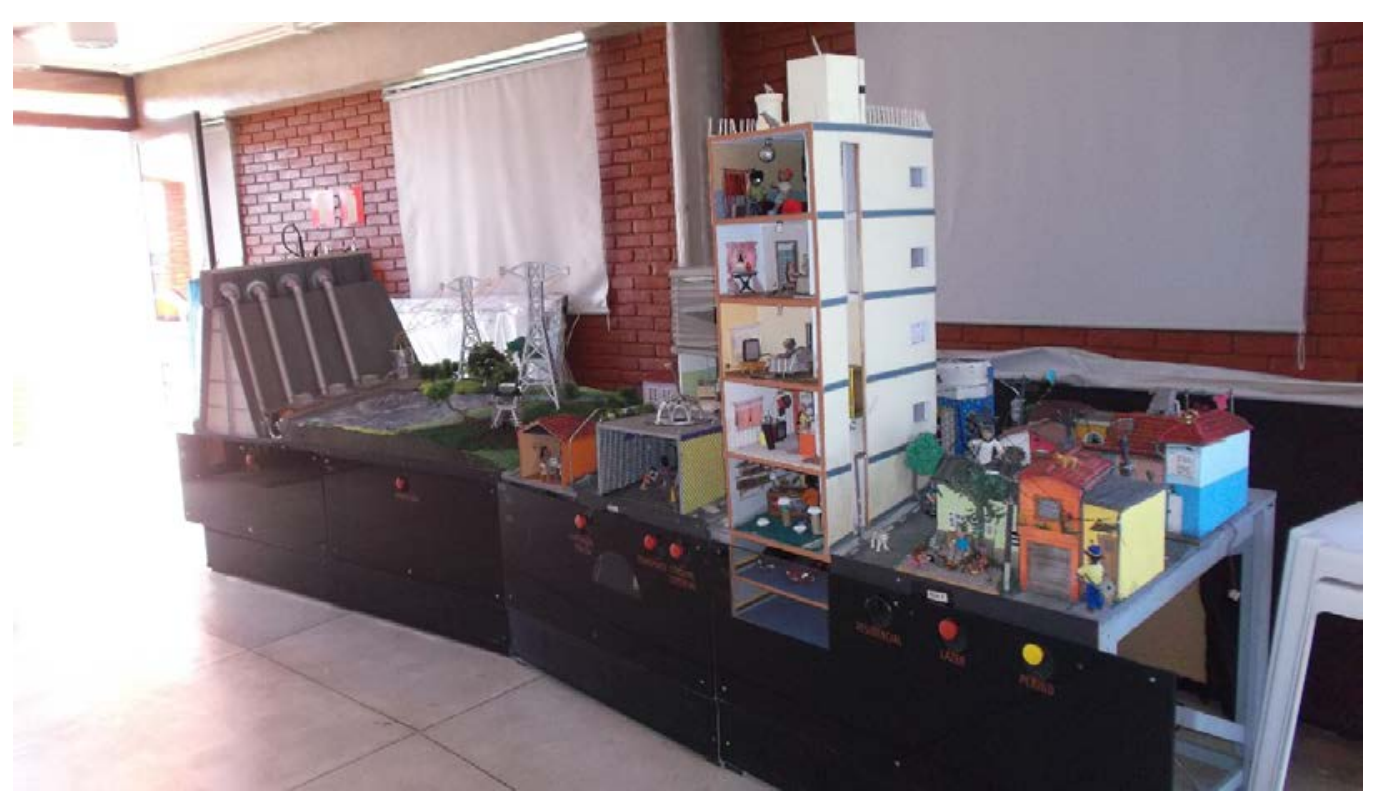

Figura 1 - Maquete que descreve o processo de geração, distribuição e consumo de energia, a partir de uma usina hidrelétrica.

Acervo do Museu Exploratório de Ciências da UNICAMP, como parte da exposição 'Energia'- foto dos autores.

A maquete reproduz literalmente um rio, partes da usina, prédios e casas com personagens que ilustram, através de suas ações, o contexto no qual a energia exerce um papel fundamental, como o consultório de um dentista, uso de eletrodomésticos em residências, trabalhadores com máquinas, etc.

A interação do usuário com essa maquete é basicamente visual. Nesse sentido, ela faz o papel de uma grande ilustração ${ }^{4}$ de todo o processo, fazendo com que o público, através das imagens estáticas propostas por ela, o compreenda. Como ilustração, a maquete se encarrega de mimetizar a realidade, reproduzindo de forma literal, os cenários envolvidos. O reconhecimento de todos os elementos que fazem parte do processo é imediato: o rio, as tubulações, a representação da cidade, os personagens em suas funções, são imediatamente identificados, o que provoca uma correspondência direta com o texto explicativo ou mediação do guia.

A partir dessa correspondência, para além da apreensão do conteúdo, o observador, recorrendo à sua imaginação diante desse arsenal imagético, pode criar seu texto paralelo, dando vozes aos personagens, imaginar as ações e enriquecer a narrativa original acionando seu próprio repertório, da mesma forma que as ilustrações exercem

${ }^{4}$ Como ilustração entendemos imagens que geralmente acompanham um texto escrito, ou que visam informar, através de esquema gráfico, processos e ou ações, como nos livros científicos e manuais ilustrados. Trata-se principalmente de informações através de imagens. 
na literatura, no interior de um livro ricamente ilustrado. Dessa forma, consolida-se ao observador que entra em contato com a maquete informativa, uma experiência, que dá um outro sentido ao processo de aprendizagem ou leitura, fora do contexto tradicional da sala de aula, onde o conteúdo é estático, retirado dos manuais escolares, sem ligação direta com a vivência do aluno.

Daí a importância do papel dos museus e instituições similares, na educação escolar. Essas instituições possuem meios de proporcionar ao aprendiz uma aproximação do conhecimento, de forma diferenciada, através de produtos, objetos ou dinâmicas que lhes são próprias.

Não se trata de simplesmente reforçar o conteúdo ,mas, antes, ampliá-lo, possibilitando uma vivência e aproximação do tema de outra forma que não o tradicional processo de repetição por muitas vezes limitado à escola. O nosso sistema tradicional de ensino trabalha com a transmissão de conhecimentos prontos e acabados e tem dificuldade em compreender a transmissão do conhecimento ligado à vida do aluno, através da relação que se estabelece com o saber. Nas instituições onde o aluno tem oportunidade de "experenciar" ou, ter o saber como experiência vivida, ele vivencia o processo educativo de forma participativa e diferenciada. ${ }^{5}$

A referida maquete, rica em conceitos e significados, no entanto, para o deficiente visual se torna acessível apenas através de uma descrição, mediada por um guia, que descreve a seu modo, os personagens e suas ações. Sem a fruição direta, o processo pode ficar restrito e a experiência empobrecida. Em se tratando, como já foi dito, de uma grande ilustração de um processo - e aqui reiteramos o papel da ilustração como motor da experiência, o resultado dessa experiência mediada é basicamente o mesmo de se confrontar uma imagem para a qual se atribui uma legenda que determina de antemão seu sentido, restringindo a autonomia do observador perante as múltiplas possibilidades de produção de sentido.

Normalmente, ao se descrever algo para um deficiente visual, há um imperativo que limita a experiência. Dizer "isso é determinada coisa", é bem diferente do perceber e descobrir por si mesmo, quando se trata de uma experiência estética. Para o deficiente visual, então, fica interrompida a fase mais rica, de acionar sua imaginação, seu repertório pessoal e construir, por ele mesmo, os sentidos da experiência.

Então como proporcionar essa experiência ao deficiente visual, permitir que ele trafegue por um caminho de metáforas que possam servir como motores de imagens mentais, associações e formação de repertório, permitindo sua autonomia?

O desafio proposto foi a criação de uma estação acessível que representasse todo o processo descrito na maquete, de forma interativa, para o público deficiente visual.

Evitamos partir dos recursos que são, automaticamente, apresentados como alternativas para esse público: textos descritivos em braille ou seu equivalente em áudio-descrição mas, antes pensamos que o som poderia ser explorado de forma mais ampla do que apenas a serviço de uma locução.

O braille, por sua vez, seria utilizado somente para fornecer instruções de uso da estação.

Sendo assim, ao invés do binômio cores e formas, partimos para a combinação entre sons e formas.

\footnotetext{
5 Tomamos por base o conceito de "educação como reconstrução da experiência" do filósofo e pedagogo John Dewey, no sentido de valorização da experiência para além da transmissão do conhecimento de forma puramente estática e livresca.
} 


\section{10 SOM}

Inicialmente recorremos ao conceito de "paisagem sonora". Esse conceito derivou dos estudos do músico Murray Schaffer, que utilizou os sons ambientes como forma de sensibilizar a audição e, por meio dela, compreender o espaço que nos rodeia de uma forma que vai além da visão. Preocupado com o excesso de ruídos da cidade e seus efeitos sobre a percepção auditiva, Schaffer procurava cada vez mais utilizar os sons ambientes como elementos possíveis para composições musicais ${ }^{6}$.

Procuramos então, sob essa influência, criar uma ambientação ou, paisagem sonora, composta pelos sons dos ambientes propostos pela maquete original: o rio e os sons da natureza, queda e pressão da água, movimento das turbinas, geradores, personagens e sons da cidade. Tudo o que na maquete original era representação estática, ganhou um grande dinamismo através do som.

Para que essa paisagem sonora chegasse ao público cego, foi utilizado o dispositivo Pentop. Essa "caneta", amplamente utilizada para leitura e áudio-descrição, foi programada para identificar, através de leitor ótico, pontos que disparassem os áudios que representavam os sons ambientes. Com fone de ouvido, o deficiente visual poderia identificar e localizar no espaço, momentos do processo de geração e utilização de energia elétrica.

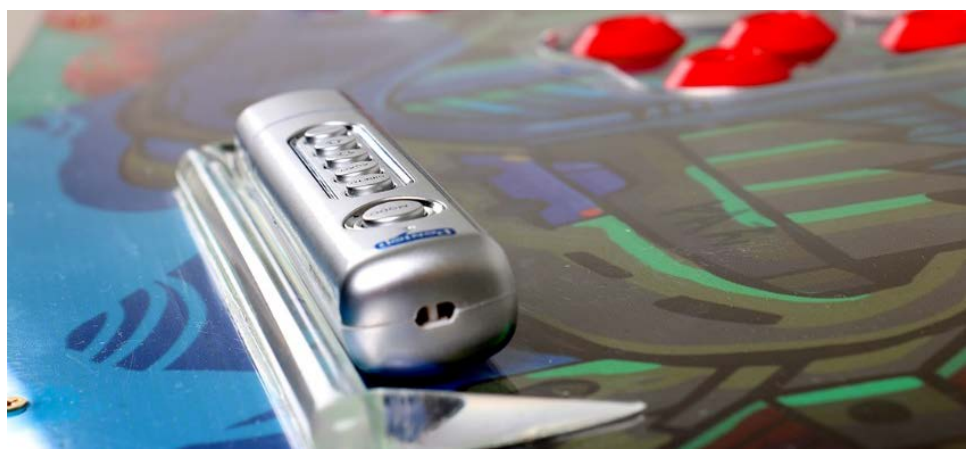

Figura 2 - O leitor ótico 'Pentop', como recurso para a ativação das paisagens sonoras - Foto dos autores

Os sons ambientes foram gravados sem utilizar nenhuma locução que pudesse funcionar como legenda mas, que possibilitassem uma experiência sensível, poética, na qual o fruidor pudesse acionar as próprias referências e construir sentidos diversos, ao mesmo tempo em que assimilassem o processo.

O Conjunto de paisagens sonoras utilizadas no projeto pode ser acessado através do link: https://www.youtube.com/playlist?list=PLoBB_-rvhPJZLVtT6BNhXIS6XriuoRO4R

\section{2 - A FORMA}

Sabemos que, para o cego, o mundo se dá através do tridimensional. A cadeira, por exemplo, existe em sua tridimensionalidade e mais ainda, pela relação corporal com ela. O sistema sensorial háptico ou tato ativo é a busca intencional de informações através do tato, que geralmente são mediadas pelas informações de videntes, e que, por sua vez possuem processo de formação de imagens mentais diferentes. Isso às vezes abre uma lacuna ou acabam por não possibilitar uma autonomia do deficiente visual para

\footnotetext{
${ }^{6}$ Schaffer, Murray. O ouvido pensante. São Paulo: Editora UNESP, 2000
} 
interpretação da forma tátil.

O contorno ou a textura, por si só, não é facilmente reconhecido pelo cego. $\mathrm{O}$ tato não é o equivalente imediato do visual, como o senso comum propaga.

Vemos essa crença no universo da literatura para crianças cegas que trabalham a textura do papel ou as ilustrações em relevo como forma de oferecer a ilustração que originalmente acompanha o texto mas, nem sempre isso funciona como algo complementar a ele. Porque ilustrações são imagens bidimensionais. E retratam coisas que não existem da mesma maneira para um cego.

Os livros didáticos em arquivos sonoros possuem uma regulamentação de descrição das imagens, como se a descrição detalhada fosse equivalente ao visual, mas acaba enchendo de informações burocráticas, repetitivas, como cores e se a tipografia aparece com ou sem serifa, que não traduzem, de fato, uma experiência similar ao que os elementos gráficos oferecem aos videntes.

O Braille que, indiscutivelmente é um recurso que possibilita a transposição de muitas barreiras, nem sempre dá conta de possibilitar uma experiência como a que se tem diante de uma maquete complexa em um museu. Mas foi usado como primeiro mediador entre o usuário e a estação, fornecendo a primeira instrução de colocação de fone e utilização da Pentop.

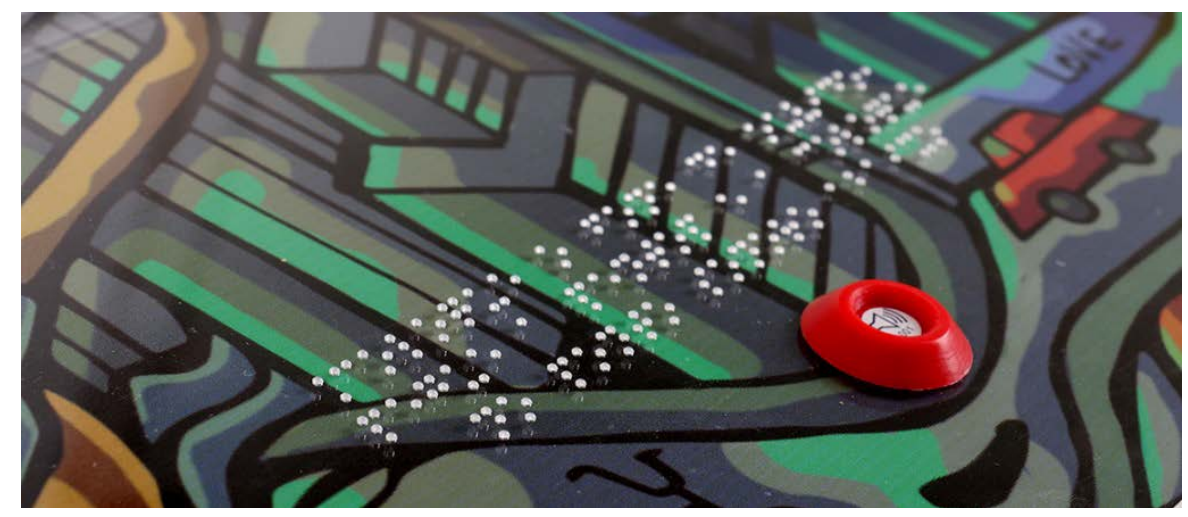

Figura 3 - As instruções iniciais são fornecidas em Braille. - Foto dos autores

Partindo dessas premissas, o som, aliado a um percurso tátil, deveria criar uma relação dialógica que, de forma poética, transportasse o usuário pelo cenário da maquete original.

A estação, para conforto e praticidade do usuário foi projetada como uma mesa, onde o usuário pudesse utilizar fone de ouvido, o dispositivo Pentop e, através de dois planos diferentes, relevos e vibração, pudesse vivenciar o processo e compreender de forma autônoma o que se propunha. 


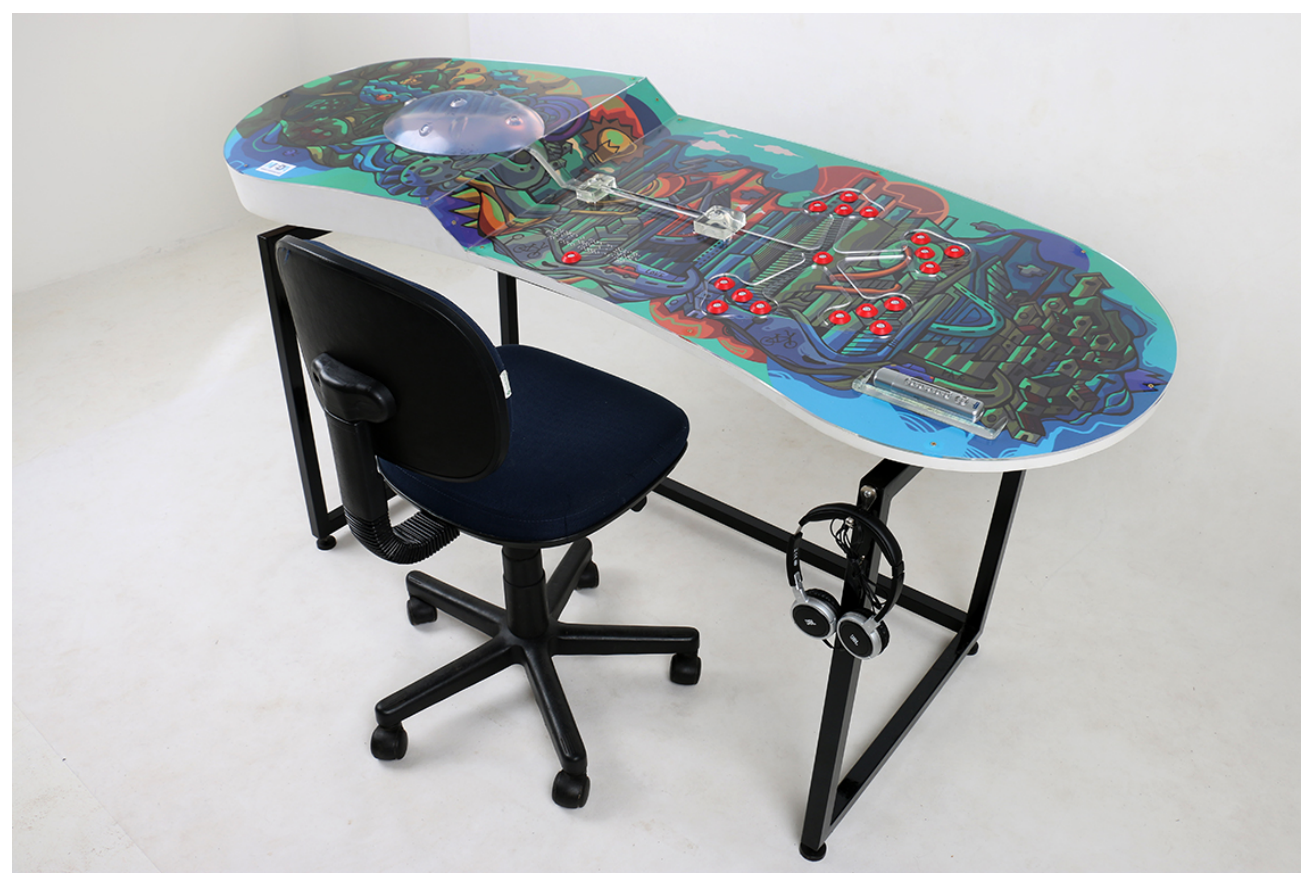

Figura 4 - 0 conjunto da estação multissensorial

O caminho que conduzia a passagem de um ponto sonoro a outro não poderia ser simplesmente uma linha condutora mas, teria que dialogar com o som, criar uma relação onde forma e som tivessem o mesmo estatuto semântico.

O ponto de partida, a represa, foi representada por uma peça de resina transparente, em formato de grande gota d'água, que afunilava e descia para o plano mais baixo da maquete. Dessa forma, através do tato seria possível perceber, além do ambiente represa, onde poderia ser experimentado quatro pontos diferentes para localização no cenário natural, além disso, utilizando uma metáfora do movimento da água, que essa era represada e que sua queda daria início ao processo de geração de energia na usina hidrelétrica.

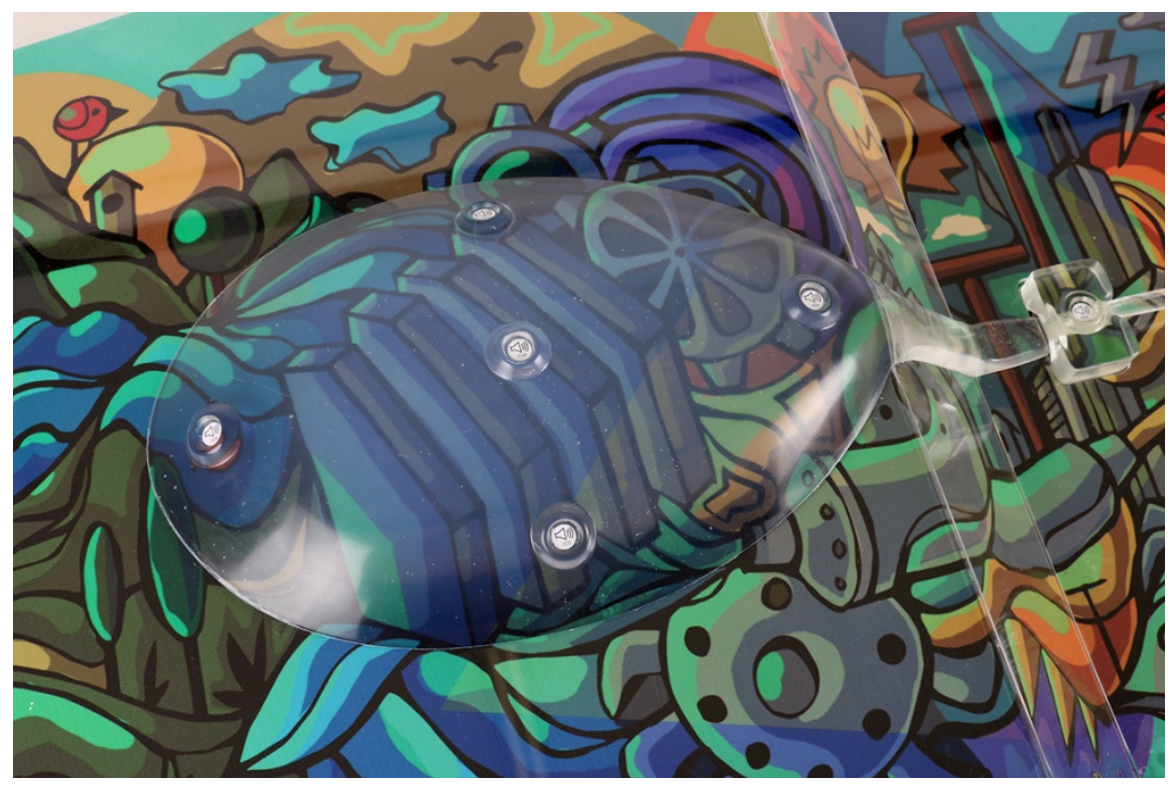

Figura 5 - A represa e a barragem, são representados por uma peça translúcida fundida em resina de poliéster, em formato de gota que escorre de um plano a outro mais baixo, simulando o deslocamento da água que gira as turbinas de uma usina hidrelétrica - Foto dos autores 
A fabricação digital foi um processo importante na obtenção de moldes para as peças que compunham o percurso tátil, que depois foram moldados em resina e acoplados dispositivos para outros recursos que, aliados ao som, possibilitassem uma melhor experiência.

$\mathrm{O}$ arquivo sonoro que representava a energia sendo gerada pela turbina, localizou-se em um dispositivo vibratório, causando a sensação de que a energia pudesse ser algo palpável. A falta de possibilidade de visualizar um gerador foi substituída pela sensação tátil e sonora do que entendemos como "energia". Mais uma vez recorre-se à metáfora para possibilitar uma experiência sensorial.

\section{CONCLUSÃO}

O resultado final do projeto foi apresentado a um grupo de deficientes visuais, no contexto da exposição 'Energia', do Museu de Ciências da UNICAMP. Constatou-se que, conforme o esperado, cada visitante foi capaz de acionar seu próprio repertório, e de forma autônoma, fruiu de uma experiência nova na qual os conceitos científicos associaram-se a uma experiência sensível e poética. A experiência reforçou o sentido de que, uma abordagem descritiva apoiada pelo design e sonoplastia, pode ampliar a eficácia de aquisição de conhecimento através de um formato menos burocrático e técnico, mais livre e poética.

Caminha-se desta forma na direção de validar a premissa fundamental da pesquisa, que declara que os métodos áudio descritivos consolidados pautados essencialmente no recurso da palavra, podem tornar-se mais eficientes e efetivos em seus objetivos de transmitir conceitos do mundo concreto a deficientes visuais, se forem relacionados a meios que permitam associações metafóricas na construção de significados, através de seus principais canais de percepção do mundo físico e do espaço, que são precisamente os sentidos do tato e da audição.

Nesta direção, espera-se que as reflexões levantadas por esse projeto possam contribuir com o debate orientado a produzir métodos de produção de materiais didáticos de baixo custo, para públicos especiais. Não obstante o principal interesse deste artigo em particular, seja descrever como as soluções de projeto foram orientadas por diretrizes de ordens diversas, tais como aspectos cognitivos, educacionais e estéticos, a pesquisa em seu escopo mais amplo envolve o forte interesse no uso da fabricação digital que, além do baixo custo na produção, permite ainda a disponibilidade de arquivos compartilháveis e, dessa forma um maior disseminação dos conteúdos.

\section{REFERÊNCIAS}

BRASIL. Decreto no. 5.296, de 2 de dezembro de 2004. Regulamenta as leis no. 10.048, de 8 de novembro de 2000 , que dá prioridade de atendimento `as pessoas que especifica, e no. 10.098 , de 19 de dezembro de 2000, que estabelece normas gerais e critérios básicos para a promoção de acessibilidade das pessoas portadoras de deficiência ou com mobilidade reduzida, e dá outras providências. Diário Oficial da União. Brasília, 2004.

BRASIL. Parâmetros curriculares Nacionais: Adaptações Curriculares. Brasília, 1998. Disponível em www.educacaoonline.pro.br/adaptacoes_curriculares,asp

BARTHES, R. "Rhétorique de l'image". (in: Communications, n. 4, 1964)

CAMARGO, Eder Pires. Saberes docentes para a inclusão do aluno com deficiência visual 
em aulas de Física. São Paulo: Unesp, 2012

CARVALHO, E.N.S.; MONTE, F.R.F. A educação inclusiva de portadores de deficiências em escolas públicas do DF.Temas em Educação Especial III. São Paulo: Editora Universidade de São Carlos,1995

DIMBLERY, R.; BURTON, G. Mais do que palavras: uma introdução à teoria da comunicação. 4.ed.São Paulo: Cortez, 1990

FRANÇA, V.V. O objeto da comunicação: a comunicação como objeto. In: HOHLFELDT, A. et. al. (Org.) Teoria da comunicação: conceitos, escolas e tendências 5, ed. Petropolis: Vozes, 2005

MASINI, E,F.S. Impasses sobre o conhecer e o ver. In: 0 perceber e o relacionar-se do deficiente visual: orientando professores especializados. Brasilia: Corde, 1994

MITTLER, P. Educação inclusiva: contextos sociais. São Paulo: Artmed, 2003

PARRA, N.; PARRA, I. C.C. Técnicas audiovisuais de educação 5.ed. São Paulo: Pioneira, 1985

TARDIF, M. Saberes docentes e formação profissional. Petrópolis: Vozes, 2004

SCHAFFER, M. O ouvido pensante. São Paulo: Unesp, 2000

VIGOTSKI, L.S. Fundamentos da defectologia: el niño ciego. In: Problemas especiales da defectologia. Havana: Editorial Pueblo y Educación, 1997.

ZABALA, A.A. A prática educativa: como ensinar. Porto Alegre: Artmed, 1998

BONSIEPE, Gui. Do material ao digital. São Paulo: Blucher, 2015

MCCULLOUGH, Malcolm. Abstracting Craft: The Practiced Digital Hand, Massachussets: MIT Press, 1998.

FLUSSER, Vilém. O mundo codificado. São Paulo: CosacNaify, 2007

BRITO, Jorge; COELHO, Luiz. Fotogrametria digital. 1. ed. Rio de Janeiro: IME - Instituto Militar de Engenharia, 2009. 